\title{
Methotrexate Versus Methotrexate Plus Folic Acid in the Treatment of Moderate to Severe Plaque Psoriasis: A Randomized Clinical-Trial
}

\author{
Khadka DK' ${ }^{1}$, Agrawal S², Dhali TK \\ ${ }^{1}$ Assistant Professor, Department of Dermatology and Venereology, B. P. Koirala Institute of Health Sciences, Dharan, \\ Nepal; ${ }^{2}$ Professor and Head, Department of Dermatology and Venereology, B. P. Koirala Institute of Health Sciences, \\ Dharan, Nepal; ${ }^{3}$ Associate Professor, Department of Dermatology and Venereology, ESIC PGIMSR, New Delhi, India
}

\begin{abstract}
Background: Psoriasis is a chronic, recurring inflammatory disease affecting the skin, joints and nails that has a significant negative impact on the quality of life. Efficacy of methotrexate versus combination of methotrexate plus folic acid in the treatment of psoriasis has been rarely assessed.

Objectives: To compare the efficacy of methotrexate versus methotrexate plus folic acid in the treatment of moderate to severe chronic plaque psoriasis

Material and Methods: Eighty patients with moderate to severe chronic plaque psoriasis were randomized to receive either methotrexate (group A) or methotrexate plus folic acid (group B). End point of treatment was $75 \%$ reduction in Psoriasis Area and Severity Index (PASI 75) score or upto 3 months, whichever was earlier. Patients were then followed up for a period of 12 weeks for assessment of relapse, DLQI and adverse effects.

Results: Of 80 patients, 71 completed the treatment and follow up period ( 33 in group A, and 38 in group B). PASI 75 was achieved in $34 / 40(85 \%)$ patients in group $A$ and $32 / 40(80 \%)$ patients in group $B(P<0.142)$. There was statistically significant number of patients who had greater adverse effect in methotrexate than in methotrexate plus folic acid $(p=0.020)$. There was significant difference in the number of patients who relapsed during the follow-up period $(P=0.013)$ with more relapse in group $B$.
\end{abstract}

Conclusion: Combination of methotrexate and folic acid developed lesser adverse effect and greater relapse in comparison to methotrexate alone.

Key words: DLQI, Folic acid, Methotrexate, PASI, Psoriasis

\section{Introduction}

$\mathrm{P}$ soriasis is a common, chronic, disfiguring, inflammatory and proliferative condition of the skin and has remitting and relapsing course. The characteristic lesion consists of red, scaly, sharply demarcated, indurated plaque, presents particularly over the extensor surface of the extremities and scalp. The disease is variable in duration, periodicity of flares and extent. Morphological variants are common. ${ }^{1}$ The prevalence of psoriasis varies from 1.5 to $3 \%$ and incidence indicated to 60 individuals per 100000

\footnotetext{
Address for correspondence

Dr. Dhan Keshar Khadka

Assistant Professor

Department of Dermatology and Venereology

B. P. Koirala Institute of Health Sciences, Dharan, Nepal

Ph. No: 9842026086

E-mail: dhankesharjung@gmail.com
}

per year. ${ }^{2}$ The prevalence of psoriasis is $2 \%$ in a study conducted in eastern Nepal to identify the patients profile and belief regarding the disease psoriasis. ${ }^{3}$ Psoriasis may have a major impact on quality of life and self-esteem. It can lead to limitations with daily activities, occupational functioning and relationship. ${ }^{4}$ The severity of the disease determines the therapeutic approach. ${ }^{5}$ Monotherapy with systemic agents may be insufficiently effective or produce many side-effects. In these cases, combination, rotational or sequential treatment strategies may be utilized for better results. ${ }^{3}$ Methotrexate a folic acid antagonist though effective produces many side effects associated with liver toxicity in long-term and gastrointestinal intolerance in short-term use. Folic acid supplementation found to reduce its side effects but in a recent small study, suggestions are made that supplementary folic acid might reduce the effectiveness of methotrexate. Therefore, we had planned to undertake the study 
to compare the therapeutic efficacy of methotrexate versus methotrexate plus folic acid in the treatment of moderate to severe plaque psoriasis and identify the adverse effects, Dermatology life quality index (DLQI), and relapse associated with these regimes.

\section{Material and methods}

Patients with plaque psoriasis attending the outpatient department (OPD) of Dermatology department, BPKIHS, Dharan with more than $2 \%$ BSA involvement were included and patients with less than $2 \%$ BSA, pregnant and lactating women, patients with systemic diseases and those who received systemic treatment for psoriasis within the past 4 weeks and topical treatment within the past 2 weeks, those with history of skin cancer and immunosuppression due to disease or drugs were excluded in the study. This study is an observer blinded, randomized, clinical trial and was approved by the Institutional Ethical Committee.

The sample size of 40 patients were recruited in each arm of the study, considering $80 \%$ power, $5 \%$ alpha error, two sided and percentage of PASI 75 reduction at 12 weeks in methotrexate group $50 \%$.

\section{Subject enrollment}

A prior informed and written consent was taken from all patients. Particulars of an individual patient and detailed history with respect to the chief complaints, duration of illness, associated symptoms and site of involvement were documented in a preset proforma for each patient. Seasonal variation, precipitating factors, joint involvement, family history and past treatment taken were also recorded. A complete clinical examination was done in all patients. The sites involved and the morphology of the lesion were documented in the proforma. Body surface area (BSA) was measured using the rule of nine as in burn. Severity of the disease was assessed using PASI (Psoriasis Area and Severity Index).

Baseline investigations of routine blood counts $(\mathrm{Hb}$, TLC, DLC, platelets), liver function test (total bilirubin/ conjugated, SGOT, SGPT, ALP) and renal function test (S.Urea, S. Creatinine), Urine R/M, and X-ray chest PA view were done to rule out any systemic involvement. A HIV test was done after sending the patient for the pretest counseling only in high risk patients. All females of reproductive age group underwent the pregnancy test and were also advice to use contraceptives during the treatment period.
A wash off period of 2-4 weeks was given to patients on any kind of past treatment (i.e. 2 weeks for topical and 4 weeks for any systemic treatment).

No concomitant therapy was allowed except for emollients and anti-histamines during treatment and follow-up period.

Two parallel groups (1:1) generated with the help of Ralloc software and were randomized into two intervention group. Group A (Methotrexate(MTX)) and Group B (Methotrexate plus folic acid(MTX+FA).

\section{Methotrexate (Group A)}

Oral MTX was given in the dose of $0.4 \mathrm{mg} / \mathrm{kg} /$ week with maximum of $25 \mathrm{mg} /$ week for a period of 12 weeks. No changes were permitted in the dose of MTX used during the study.

\section{Methotrexate plus folic acid (Group B)}

Oral MTX was given in the dose of $0.4 \mathrm{mg} / \mathrm{kg} /$ week with maximum of $25 \mathrm{mg} /$ week for a period of 12 weeks similar to group $A$, in addition single dose of 5 $\mathrm{mg}$ folic acid was administered 24 hours after.

\section{Assessment}

Assessment was done by calculating PASI and TBSA (\%) during follow-up. DLQI were assessed at 12 and 24 weeks using Nepali version. Relapse assessed at 16, 20 and 24 weeks of follow-up. TLC, DLC, Hb, platelets, LFT repeated twice weekly for first 4 weeks and every 4 weekly for remaining 8 weeks. Cumulative dose of methotrexate was calculated. The primary end point was change in PASI at 12 week and secondary end point was adverse effect, DLQI, and Relapse. Level of outcome measured as:

1. Excellent/good : clearance/minimal residual disease, or PASI 90

2. Satisfactory: PASI 75

3. Improvement: PASI 50

4. Mild improvement: PASI $1-<50$

5. No improvement: PASI 0

6. Relapse: PASI $>25$ from baseline

Treatment discontinuation was done if there were any serious adverse effect and if there were any abnormal laboratory findings.

\section{Statistical analysis}

Data from all randomized patients were included on intent-to treat basis. T-test was used where equal variance was demonstrated. Chi square test was 
used in the initial exploration of the data. Otherwise, equivalent nonparametric statistics (Wilcoxon rank sum test) was used. Kaplan-Meir test used to assess the relapse after completion of the treatment period.

\section{Results}

Of 116 patients, 36 patients were excluded from the study and 80 patients were randomized.

Among 80 randomized patients (40 in each group), a total of 71 (33 in Group A and 38 in Group B) completed the treatment and follow-up (Figure 1).

A baseline demographic comparison of the 2 groups (Group A and B) of patients is shown in Table 1 . The patients of both groups were not statistically different in regards to age $(p=0.475)$, duration $(p=0.867)$, PASI $(p=0.432)$, TBSA $(p=0.263)$, and DLQI $(p=0,137)$.

\section{Psoriasis area severity index (PASI)}

There was marked reduction in percentage score of PASI between the two treatment groups, however there was no statistical significance $(p=0.682)$ (Table 2). During the follow-up period of 12 weeks carried at 4 weekly interval, the mean PASI reduction at 24 weeks was also statistically not significant $(P=0.260)$ (Table 3$)$. PASI 75 was achieved at $8^{\text {th }}$ week in Group A, whereas it was at $9^{\text {th }}$ week in group $B(p=0.058)$ and the total cumulative dose of methotrexate was slightly lower in Group A than Group B ( $p=0.050)$. Both were statistically insignificant (Table 4).

\section{Total body surface area (TBSA)}

Reduction in percentage of total body surface area was marked in both the groups but was statistically insignificant $(P=0.732)$, at 12 weeks (Table 5) and during follow-up period of 12 weeks after completion of treatment (i.e. at 24 weeks) $(p=0.174)$ (Table 6).

\section{Dermatology life quality index (DLQI)}

Marked reduction in DLQI was present both at 12 weeks and at 24 weeks, however statistically significant reduction was at 12 weeks $(P=0.041)$ and favored Group A over Group B (Table 7).

\section{Adverse effects (ADRS)}

In methotrexate group, $11(27.5 \%)$, patients developed the side effects, in methotrexate plus folic acid $5(12.5 \%)$. There was statistically significant difference in side effects at the end of study among the two treatment group ( $P=0.020)$ (Table 8$)$. However the side effects were not serious.

\section{Relapse}

There was significant difference in number of patients who relapsed at the end of study among the two groups ( $p=0.013$ ) (Table 9). Higher number of patients relapsed during follow-up period of 12 weeks in methotrexate plus folic acid group compared to methotrexate alone (36.8\% vs $21 \%$ )

Table: 1: Baseline characteristics of study populations

\begin{tabular}{|c|c|c|c|c|}
\hline Characteristics & Categories & $\begin{array}{l}\text { Methotrexate } \\
\qquad(\mathrm{N}=40)\end{array}$ & $\begin{array}{l}\text { Methotrexate+FA } \\
\qquad(\mathrm{N}=40)\end{array}$ & P-value \\
\hline Age group (years) & Mean \pm SD & $41.33 \pm 16.127$ & $40.32 \pm 13.667$ & 0.475 \\
\hline Sex & $\begin{array}{c}\text { Male } \\
\text { Female }\end{array}$ & $\begin{array}{c}25(62.5 \%) \\
15(37.5)\end{array}$ & $\begin{array}{l}22(55 \%) \\
18(45 \%)\end{array}$ & 0.771 \\
\hline Duration(yrs) & Mean $\pm S D$ & $3.38 \pm 1.628$ & $3.55 \pm 1.739$ & 0.867 \\
\hline Family history & $\begin{array}{l}\text { Present } \\
\text { Absent }\end{array}$ & $\begin{array}{c}3(7.5 \%) \\
37(92.5 \%)\end{array}$ & $\begin{array}{c}8(20 \%) \\
32(80 \%)\end{array}$ & 0.247 \\
\hline PASI & Mean \pm SD & $10.97 \pm 5.903$ & $11.93 \pm 7.586$ & 0.432 \\
\hline TBSA & Mean $\pm S D$ & $20.55 \pm 15.30$ & $22.08 \pm 19.49$ & 0.263 \\
\hline DLQI & Mean $\pm S D$ & $10.20 \pm 5.36$ & $10.77 \pm 5.52$ & 0.137 \\
\hline Methotrexate dose & Mean $\pm S D$ & $12.5 \pm 10.05$ & $13.5 \pm 8.64$ & 0.266 \\
\hline
\end{tabular}


Khadka DK et al.

Table 2: Change in PASI during treatment

\begin{tabular}{|c|c|c|c|c|c|c|c|}
\hline Characteristics & & Group & & & & \\
\hline weeks & $\mathrm{N}$ & MTX & $\mathrm{N}$ & MTX+FA & Tests* & P-value & Remarks \\
\hline & & Mean \pm SD (Median) & & Mean $\pm S D$ (Median) & & & \\
\hline PASI 0 & 40 & $10.97 \pm 2.838(9.45)$ & 40 & $11.94 \pm 7.587(10)$ & 667.000 & 0.730 & NS \\
\hline PASI 1 & 40 & $8.34 \pm 5.101(7.19)$ & 40 & $9.05 \pm 4.518(7.58)$ & 677.000 & 0.952 & NS \\
\hline PASI 2 & 38 & $6.56 \pm 3.949(5.66)$ & 39 & $7.84 \pm 3.383(6.58)$ & 578.000 & 0.345 & NS \\
\hline PASI 3 & 36 & $3.16 \pm 1.775(2.73)$ & 39 & $4.05 \pm 1.750(3.4)$ & 516.000 & 0.739 & NS \\
\hline PASI 4 & 36 & $1.88 \pm 1.592(1.62)$ & 39 & $2.34 \pm 1.360(1.97)$ & 511.000 & 0.646 & NS \\
\hline PASI 8 & 35 & $1.097 \pm 2.165(0.95)$ & 38 & $1.44 \pm 1.729(1.22)$ & 538.000 & 0.981 & NS \\
\hline PASI 12 & 33 & $1.097 \pm 2.838(0.95)$ & 38 & $1.09 \pm 3.008(1.0)$ & 366.000 & 0.682 & NS \\
\hline
\end{tabular}

Table 3: Change in PASI during follow-up after treatment

\begin{tabular}{|c|c|c|c|c|c|c|c|}
\hline Characteristics & & Group & & & & \\
\hline weeks & $\mathrm{N}$ & $\mathrm{MTX}$ & $\mathrm{N}$ & MTX+FA & Tests* & P-value & Remarks \\
\hline & & Mean \pm SD (Median) & & Mean \pm SD (Median) & & & \\
\hline PASI 16 & 33 & $1.669 \pm 1.557(1.44)$ & 38 & $1.223 \pm 4.426(1.81)$ & 535.000 & 0.692 & NS \\
\hline PASI 20 & 33 & $1.669 \pm 1.395(1.44)$ & 38 & $1.220 \pm 4.616(1.81)$ & 322.000 & 0.089 & NS \\
\hline PASI 24 & 33 & $1.909 \pm 1.724(1.65)$ & 38 & $1.200 \pm 4.537(1.8)$ & 214.000 & 0.260 & NS \\
\hline
\end{tabular}

Table 4: PASI 75 response to treatment

\begin{tabular}{|c|c|c|c|c|c|}
\hline \multirow[t]{2}{*}{ Characteristics } & \multicolumn{2}{|c|}{ Group } & \multirow[b]{2}{*}{ Tests* } & \multirow{2}{*}{ P-value } & \multirow{2}{*}{ Remarks } \\
\hline & $\operatorname{MTX}(\mathrm{N}=40)$ & $\mathrm{MTX}+\mathrm{FA}(\mathrm{N}=40)$ & & & \\
\hline Attainment of PASI 75 & $34(85 \%)$ & $32(80 \%)$ & 560.000 & 0.142 & NS \\
\hline $\begin{array}{l}\text { No. weeks required for attaining } \\
\text { PASI } 75 \text { (mean } \pm \text { SD) }\end{array}$ & $8.5 \pm 4.5$ & $9.5 \pm 4.5$ & 587.000 & 0.058 & NS \\
\hline $\begin{array}{l}\text { Total MTX dose required for } \\
\text { attaining PASI } 75 \text { (mean } \pm S D \text { ) mg }\end{array}$ & $140.75 \pm 60.5$ & $170 \pm 40.5$ & 563.000 & 0.050 & NS \\
\hline $\begin{array}{l}\text { Total folic acid dose }(\mathrm{mg}) \text { required } \\
\text { attaining PASI } 75 \text { (mean } \pm S D)\end{array}$ & & $50 \pm 15.5$ & & & \\
\hline
\end{tabular}

Table 5: Change in Total Body Surface Area during treatment

\begin{tabular}{|c|c|c|c|c|c|c|c|}
\hline \multirow[t]{2}{*}{ Characteristics } & \multicolumn{4}{|c|}{ Group } & \multirow[b]{2}{*}{ Tests* } & \multirow{2}{*}{ P-value } & \multirow{2}{*}{ Remarks } \\
\hline & & MTX & & $\mathrm{MTX}+\mathrm{FA}$ & & & \\
\hline TBSA & $\mathrm{N}$ & Mean£SD (Median) & $\mathrm{N}$ & Mean $\pm S D$ (Median) & & & \\
\hline 0 (Baseline) & 40 & $20.55 \pm 15.30(15)$ & 40 & $22.08 \pm 19.49(16)$ & 694.500 & 0.953 & NS \\
\hline $1^{\text {st }}$ week & 40 & $18.55 \pm 15.57(13.5)$ & 40 & $19.20 \pm 17.29(13.9)$ & 658.500 & 0.795 & NS \\
\hline $2^{\text {nd }}$ week & 38 & $9.22 \pm 10.99(6.74)$ & 39 & $11.73 \pm 16.2(8.11)$ & 630.500 & 0.717 & NS \\
\hline $3^{\text {rd }}$ week & 36 & $7.16 \pm 8.347(5.3)$ & 39 & $6.147 \pm 16.50(4.48)$ & 530.000 & 0.889 & NS \\
\hline $4^{\text {th }}$ week & 36 & $5.76 \pm 4.20(4.21)$ & 39 & $4.68 \pm 15.28(3.4)$ & 539.000 & 0.987 & NS \\
\hline 5 ( $8^{\text {th }}$ week) & 35 & $4.23 \pm 4.15(3.1)$ & 38 & $4.84 \pm 15.28(3.51)$ & 527.000 & 0.839 & NS \\
\hline $6\left(12^{\text {th }}\right.$ week $)$ & 33 & $3.87 \pm 3.78(2.83)$ & 38 & $4.99 \pm 15.40(3.31)$ & 370.000 & 0.732 & NS \\
\hline
\end{tabular}

Table 6: Change in Total Body Surface Area during follow-up after treatment

\begin{tabular}{|c|c|c|c|c|c|c|c|}
\hline \multirow[t]{2}{*}{ Characteristics } & \multicolumn{4}{|c|}{ Group } & \multirow[b]{2}{*}{ Tests* } & \multirow{2}{*}{ P-value } & \multirow{2}{*}{ Remarks } \\
\hline & & MTX & & $\mathrm{MTX}+\mathrm{FA}$ & & & \\
\hline TBSA & $\mathrm{N}$ & Mean $\pm S D$ (Median) & $\mathrm{N}$ & Mean $\pm S D$ (Median) & & & \\
\hline (16 ${ }^{\text {th }}$ week) & 33 & $3.81 \pm 2.68(2.79)$ & 38 & $4.90 \pm 14.92(3.12)$ & 540.000 & 0.756 & NS \\
\hline (20 $0^{\text {th }}$ week) & 33 & $3.70 \pm 2.88(2.78)$ & 38 & $4.88 \pm 14.87(3.12)$ & 322.000 & 0.089 & NS \\
\hline (24 ${ }^{\text {th }}$ week) & 33 & $3.99 \pm 2.55(2.92$ & 38 & $5.03 \pm 14.60(3.65)$ & 204.000 & 0.174 & NS \\
\hline
\end{tabular}


Table 7: Change in Dermatology Life Quality Index

\begin{tabular}{|c|c|c|c|c|c|}
\hline \multirow[t]{2}{*}{ Characteristics } & \multicolumn{2}{|c|}{ Group } & \multirow{2}{*}{ Tests* } & \multirow{2}{*}{ P-value } & \multirow{2}{*}{ Remarks } \\
\hline & $\operatorname{MTX}(\mathrm{N}=40)$ & $\mathrm{MTX}+\mathrm{FA}(\mathrm{N}=40)$ & & & \\
\hline DLQI & Mean $\pm S D$ (Median) & Mean $\pm S D$ (Median) & & & \\
\hline 0 (Baseline) & $10.20 \pm 5.360(11)$ & $10.77 \pm 5.526(9)$ & 212.000 & 0.182 & NS \\
\hline 1 (12 weeks) & $1.43 \pm 2.111(1.55)$ & $2.78 \pm 3.445(2.33)$ & 200.000 & 0.041 & $\mathrm{~S}$ \\
\hline 2 (24 weeks) & $0.46 \pm 1.484(0.5)$ & $0.88 \pm 2.534(0.74)$ & 260.000 & 0.077 & NS \\
\hline
\end{tabular}

Table 8: Adverse effects

\begin{tabular}{|c|l|c|c|c|}
\hline S.N. & Side effects & MTX & MTX+FA & p-value \\
\hline 1 & A.N.V & $11(33 \%)$ & $3(7.8 \%)$ & 0.136 \\
\hline 2 & Fatigue & $7(21 \%)$ & $4(10.5 \%)$ & 0.420 \\
\hline 3 & Pruritis & $7(21 \%)$ & $5(13 \%)$ & 0.810 \\
\hline 4 & Burning sensation & $3(9 \%)$ & $4(10.5 \%)$ & 0.542 \\
\hline 5 & Mucositis & $3(9 \%)$ & $0(0 \%)$ & 0.562 \\
\hline 6 & Transaminitis & $6(18 \%)$ & $2(5.2 \%)$ & 0.678 \\
\hline 7 & Anaemia & $1(3 \%)$ & $3(7.8 \%)$ & 0.320 \\
\hline 8 & Leucopenia & $1(3 \%)$ & $2(5.2 \%)$ & 0.298 \\
\hline 9 & Thrombocytopenia & $0(0 \%)$ & $2(5.2 \%)$ & - \\
\hline 10 & Total cummulative & 39 & 25 & 0.020 \\
\hline
\end{tabular}

Table 9: Relapse

\begin{tabular}{|c|c|c|c|c|}
\hline Characteristics & Methotrexate & Methotrexate+FA & p-value & Remarks \\
\hline Relapse & N-33 & N-38 & & NS \\
\hline $1(16$ weeks) & $3(9 \%)$ & $6(15.7 \%)$ & 0.285 & NS \\
\hline $2(20$ weeks) & $5(15 \%)$ & $9(23.6 \%)$ & 0.084 & S \\
\hline $3(24$ weeks $)$ & $7(21 \%)$ & $14(36.8 \%)$ & 0.013 & \\
\hline
\end{tabular}

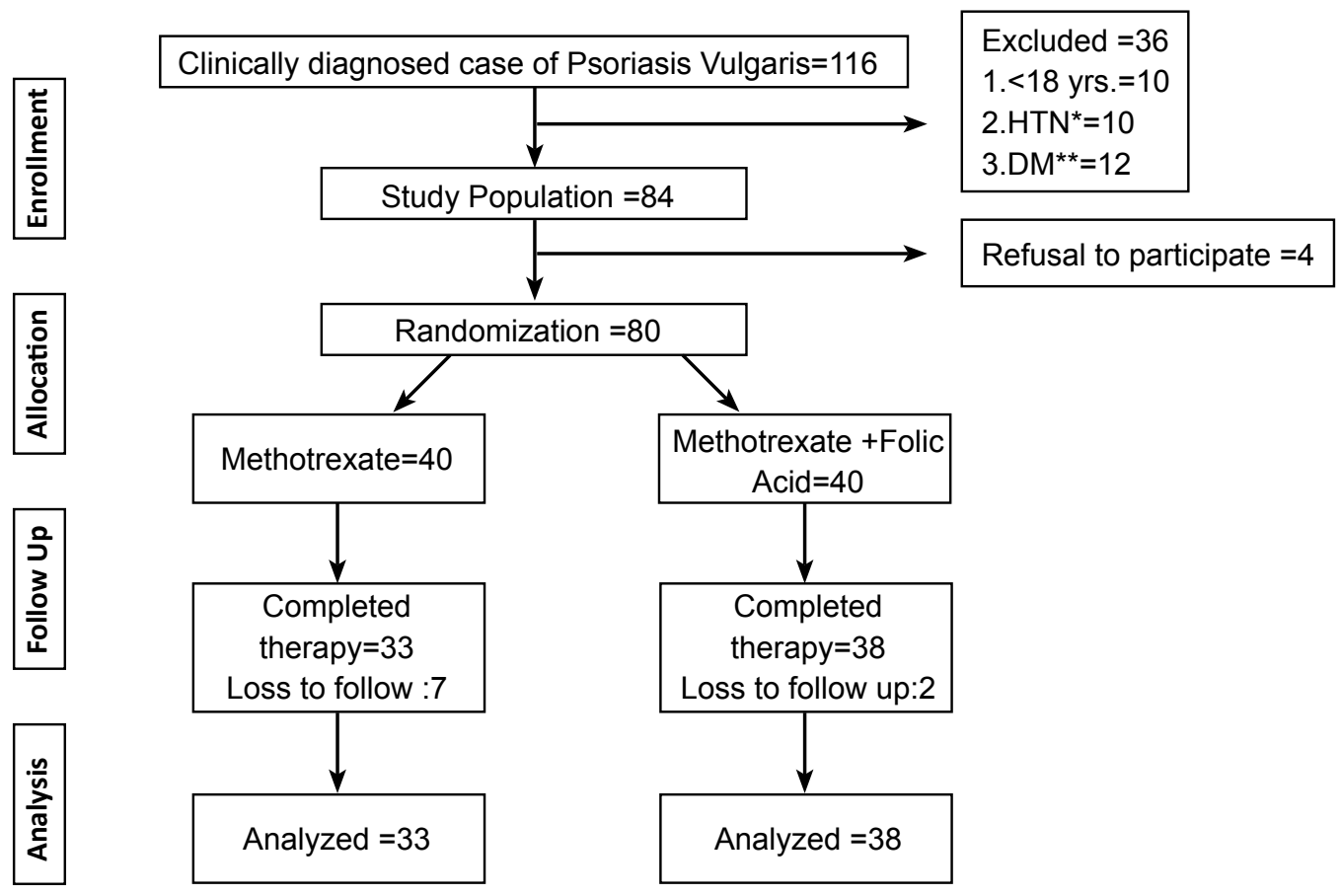

Figure 1: Flow diagram of the patients through different stages

*HTN: Hypertension, **DM: Diabetes Mellitus 


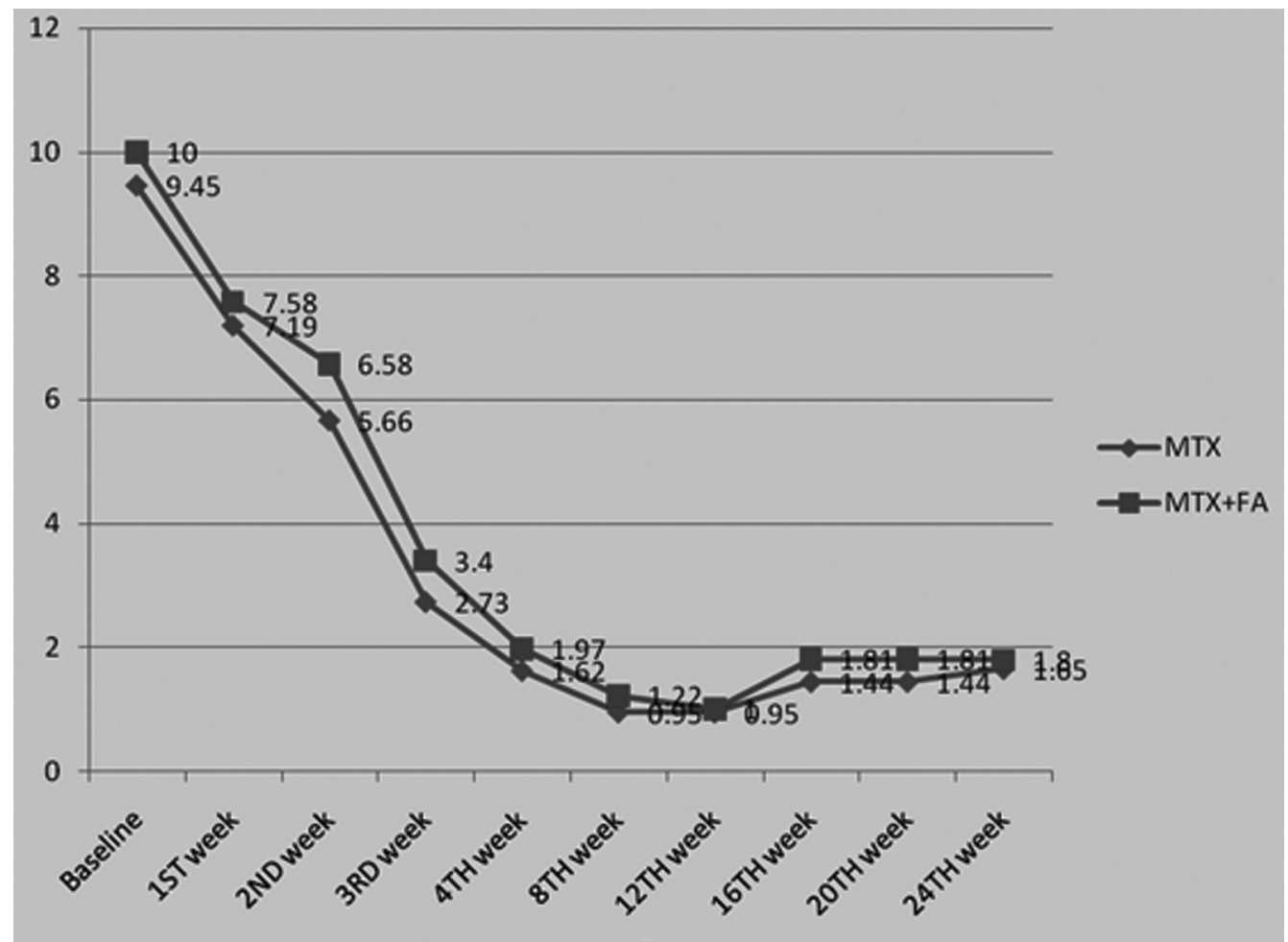

Figure 2: Change in PASI during treatment and follow-up

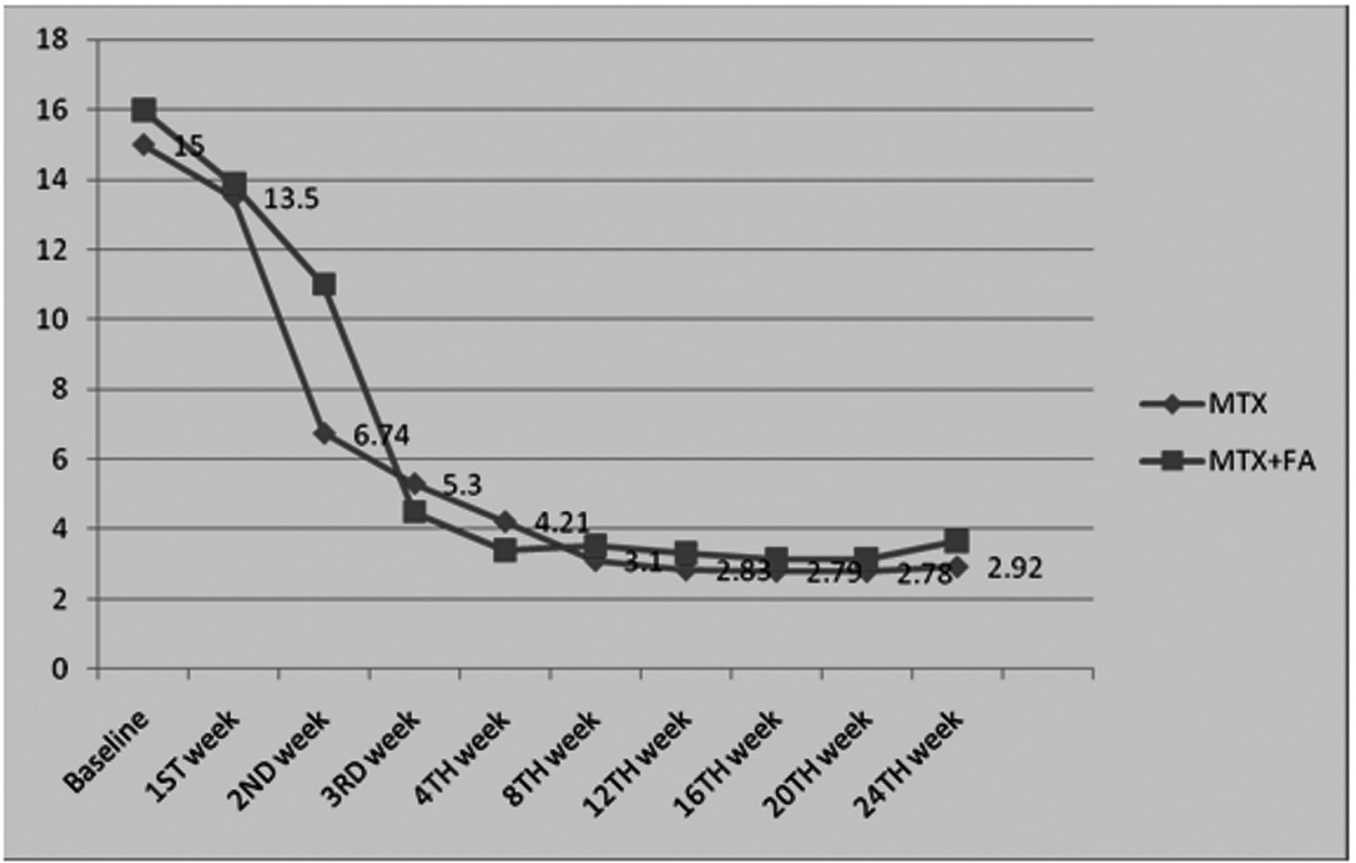

Figure 3: Change in Total Body Surface Area during treatment and follow-up 


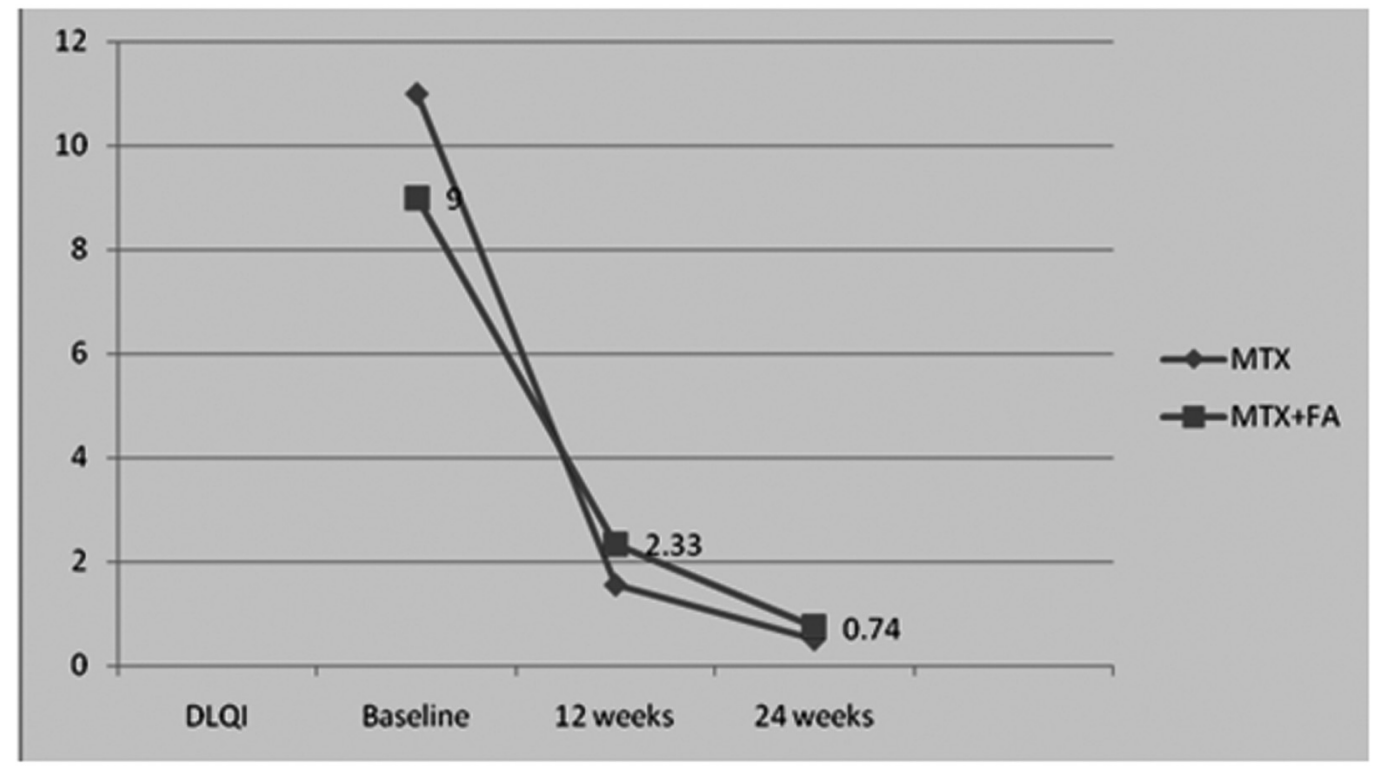

Figure 4: Change in Dermatology Life Quality Index during treatment and follow-up

\section{Discussion}

Many therapeutic agents are used for the treatment of psoriasis vulgaris with variable efficacy but none is a definite treatment. Methorexate has been in use for more than five decades as monotherapy and in combination with other agents in the treatment of psoriasis, despite its potential short-term and longterm side-effects. ${ }^{6}$

In our study, there was no statistical significant difference in the number of patients who achieved marked improvement in PASI between the two groups (methotrexate and methotrexate plus folic acid) at 12 weeks ( $P=0.682$ ). The mean total cumulative dose of methotrexate $(140.75 \pm 60.5 \mathrm{mg}$ in methotrexate, and $170.75 \pm 40.5 \mathrm{mg}$ in methotrexate plus folic acid) received by the patients in the two groups to achieve marked improvement was statistically not significant $(P=0.050)$. The difference in the time $(8.5 \pm 4.5$ weeks in Group A and $9.5 \pm 4.5$ weeks in Group B) required to achieve marked improvement in PASI to be statistically insignificant $(P=0.058)$. In our study $33 / 40$ in methotrexate (82.5\%), and $31 / 40(77.5 \%)$ in methotrexate plus folic acid achieved PASI 90 $(P=0.053)$. PASI 75 was achieved in $34 / 40(85 \%)$ in methotrexate, and $32 / 40(80 \%)$ in methotrexate plus folic acid $(P=0.072)$. During the follow-up period of 12 weeks carried at 4 weekly interval after stopping treatment, the mean PASI reduction at 24 was statistically insignificant $(P=0.260)$. Kumar et al reviewed data on 244 psoriatics who were put on weekly oral methotrexate at full therapeutic dose
(0.3-0.5 mg/kg/week) from 1981 to 2000 and found marked improvement to occur in $88 \%$ of patients in 8.5 \pm 5.1 weeks. ${ }^{7}$ These findings are similar to our findings in efficacy, dose and duration required for achieving PASI 75.

In the present study, reduction in percentage of total body surface area was statistically insignificant $(P=0.732)$, at 12 weeks of treatment and follow-up period $(P=0.174)$.

In the present study, the median reduction in DLQI between methotrexate and methotrexate plus folic acid was marked and statistically significant at completion of treatment at 12 weeks $(P=0.041)$ favouring methotrexate alone. This similar reduction in PASI, TBSA and DLQI between the two groups shows folic acid do not affect the mechanism of action of methotrexate and its efficacy.

Total of $16(20 \%)$ patients developed various side effects during treatment and follow up period among all patients in both group. In methotrexate 11 (27.5\%) patients developed the side effects; in methotrexate plus folic acid 5(12.5\%) patients developed the different side effects. There was statistically significant difference in side effects at the end of study among the two treatment group $(P=0.020)$. These side effects were graded in a 4 point scale (from 0 -no side effect to 3-severe) to know the severity of side effect. Majority of patients experienced grade 1 (mild) and few developed moderate degree of symptoms only and which disappeared on continuation of treatment. Majority 
of side effects were gastrointestinal intolerance, like anorexia, nausea, and vomiting, followed by fatigue and malaise and pruritus. Folic acid supplementation decreases the side effects of methotrexate without affecting its efficacy. Gastrointestinal side effects are predominantly due to depletion of folic acid by the action of methotrexate (Folate antagonist).

Relapse in any patients were said to be present when there was more than $25 \%$ increase in PASI score from that of PASI score at the end of treatment. There were significant number of patients who relapsed at the end of follow-up ( 24 weeks) in methotrexate plus folic acid group (14) compared to methotrexate alone (7) $(p=0.013)$. This higher relapse rate in folic acid supplementation group could be due to faster loss of effect of methotrexate by folic acid.

\section{References}

1. Raychaudhari SP, Run G, Farber EM. Neuropathogenesis and neuropharmacology of psoriasis. Int J Dermatol 1995; 34: 685-93. http://dx.doi.org/10.1111/j.1365-4362.1995. tb04653.x

2. Griffiths CEM, Camp RDR, Barker JNWN. Psoriasis. In: Burns T, Breatnach S, Cox N, Griffiths C, editors. Rooks textbook of dermatology.7th ed. Blackwell publishing 2005; p35:1-69.

3. Agrawal S, Garg VK, Agrawal A. Study to identify patients profile and belief regarding disease psoriasis in eastern Nepal. Ind J Dermatol Venereol Leprol 2003;14: 321-8.
The study concludes that the supplementation of folic acid with methotrexate do not affect its efficacy and decreases the adverse effect of methotrexate both gastrointestinal and hepatotoxicity. The gastrointestinal adverse effect particularly the nausea and vomiting decreases the compliance of oral methotrexate and hampers its efficacy thereby increasing the morbidity of psoriasis. In addition decrease in hepatotoxicity will prevent the mortality associated with the psoriasis. However folic acid supplementation group have higher relapse, it could be because of faster loss of effect of methotrexate due to folic acid. Further randomized studies with longer follow-up are required to support these findings.
4. Finlay AY, Coles EC. The effect of severe psoriasis on the quality of life of 369 patients. $\mathrm{Br}$ Jour of Dermatol 1995; 132: 236-44 http://dx.doi. org/10.1111/j.1365-2133.1995.tb05019.x.

5. Michael P, Schon W, Boehncke H. Psoriasis. New Eng J Med 2005; 352: 1899-912. http:// dx.doi.org/10.1056/NEJMra041320

6. Saporito FC, Menter MA. Methotrexate and psoriasis in the era of new biological agents. J Am Acad Dermatol 2004; 50: 301-9. http:// dx.doi.org/10.1016/S0190-9622(03)00803-X

7. Kumar B, Saraswat A, Kaur I. Short-term methotrexate therapy in psoriasis: a study of 197 patients. Int J Dermatol 2002; 41: 444-8. http://dx.doi.org/10.1046/j.13654362.2002.01530.x 